\title{
COUGH
}

\section{Association of genetic variations in neurokinin-2 receptor with enhanced cough sensitivity to capsaicin in chronic cough}

\author{
H-K Park, S-Y Oh, T-B Kim, J-W Bahn, E-S Shin, J-E Lee, H-B Oh, Y-K Kim, T Park, \\ S-H Cho, K-U Min, Y-Y Kim
}

See end of article for authors' affiliations

\section{Correspondence to:} Dr Y-K Kim, Department of Life Sciences, Pohang University of Science and Technology, San 31 Hyojadong, Pohang Kyungbuk 790-784, Republic of Korea; juinea@ postech.ac.kr

Received 25 October 2005 Accepted 3 July 2006 Published Online First 7 August 2006
Background: Chronic cough is associated with increased sensitivity to inhaled capsaicin, and both tachykinins and their receptors play important roles in the cough reflex. However, associations between polymorphisms of the tachykinin receptor genes and cough sensitivity in patients with non-productive chronic cough have not been reported.

Methods: Direct sequencing was used to identify single nucleotide polymorphisms (SNPs) in the genes for the neurokinin-1 and neurokinin-2 receptors (NK-1R and NK-2R, respectively). Informative nonsynonymous SNPs were scored using the single base extension method for 312 patients with chronic cough and for 100 age matched healthy controls. The cough response to capsaicin was recorded for 312 patients with chronic cough, and the potential genetic association between cough sensitivity to capsaicin and the NK-1R and NK-2R genotypes was evaluated.

Results: Two informative SNPs were identified in NK-2R (Gly231Glu and Arg375His), whereas no informative SNP was found in NK-1R. After adjusting for atopy, sex, age, and smoking, the prevalence of enhanced cough sensitivity to capsaicin was higher in the chronic cough patients with the 231Glu allele ( $p=0.004 ;$ OR 1.69 (95\% Cl 1.18 to 2.42)) and the 231Glu_375Arg haplotype ( $p=0.003$; OR 1.71 (95\% $\mathrm{Cl} 1.20$ to 2.24)]. Moreover, the lowest capsaicin concentration to cause five consecutive coughs (C5) was significantly lower in patients with 231 Glu (mean (SD) 44.1 (53.2) v 60.9 (55.8) $\mu \mathrm{M} / \mathrm{I}, \mathrm{p}=0.04$ ) and those with 231Glu_375Arg (43.2 (52.7) v $69.6(52.0) \mu \mathrm{M} / \mathrm{l}, \mathrm{p}=0.03)$.

Conclusions: The results of this study suggest that $N K-2 R$ gene polymorphisms are involved in the enhanced cough sensitivity to capsaicin of patients with chronic cough.
$\mathrm{C}$ hronic cough, which is defined as a cough that persists for more than 3 weeks, is a common and sometimes distressing clinical problem. ${ }^{12}$ It is believed to be predominantly caused by postnasal drip syndrome, asthma, eosinophilic bronchitis, gastro-oesophageal reflux disorder, and by drugs such as angiotensin converting enzyme inhibitors. ${ }^{3-5}$ However, in some chronic cough patients the underlying disorder is difficult to identify despite intensive investigation.

Coughing is an airway defensive reflex that is manifested as a modified respiratory tract and activation of sensory receptors in the upper and lower respiratory tracts. ${ }^{6}$ The afferent pathways associated with coughing involve receptors in and under the airway epithelium. These receptors adapt rapidly, with thin myelinated fibres in the vagus nerves, and can be directly stimulated by tussive agents. Although airway rapidly adapting receptors (RARs) can mediate the cough reflex, evidence suggests that bronchial C-fibre receptors are also involved in the cough reflexes of guinea pigs and humans. ${ }^{78}$ The sensitivity of the cough reflex and its response pattern can therefore be attributed to a complex interaction between the C-fibre receptors and RARs, in combination with peripheral and central nervous system interactions. ${ }^{9}$

Capsaicin, which is the principal component of pepper extract, is a commonly used cough stimulant in studies of cough sensitivity and for the evaluation of antitussive agents in humans. ${ }^{10}$ Vanilloid receptor-1 (TRPV-1), which mediates the cough response induced by capsaicin, is expressed in the sensory nerves that innervate the airway wall. ${ }^{11}$ It is known that C-fibre endings are sensitive to capsaicin and that RARs are insensitive to capsaicin. ${ }^{12}$

Neuropeptides, particularly tachykinins (TKs), are involved in heightened cough receptor sensitivity. ${ }^{13}{ }^{14}$ Mammalian TKs such as substance P (SP) and neurokinin A (NKA), but not $\mathrm{NKB}$, are present in the sensory nerve fibres in the upper and lower airway tracts of various mammalian species including humans. ${ }^{15}$ TKs are released from these afferent nerves as "efferent" stimuli at a peripheral level, especially in response to irritant stimuli. TKs are known to exert a variety of biological effects such as bronchoconstriction, plasma protein extravasation, and mucus secretion, which constitute "neurogenic inflammation."16 The process of TK release is believed to be of relevance for cough sensitivity. ${ }^{14} 15$ Many studies have suggested that neurokinin receptor 1 (NK-1R; tachykinin receptor $1, \mathrm{TAC} 1 \mathrm{R}$ ) and neurokinin receptor 2 (NK-2R; tachykinin receptor 2, TAC2R) play important roles in the cough reflex, whereas the role of neurokinin receptor 3 (NK-3R) has not been elucidated..$^{13} 1518$

Some patients with chronic cough show increased sensitivity to inhaled capsaicin. ${ }^{19}{ }^{20}$ Cough sensitivity in humans may be modified by host factors such as the sex of the patient, and by acquired environmental factors such as smoking and allergic inflammation. ${ }^{121-23}$ In terms of the genetic contribution to the development of cough, previous findings have suggested that susceptibility to chronic cough

Abbreviations: $\mathrm{C} 5$, lowest capsaicin concentration that elicits five consecutive coughs; RAR, rapidly adapting receptors; NK, neurokinin; SP, substance P; SNP, single nucleotide polymorphism; TK, tachykinin 
development is not associated with the ACE genotype. ${ }^{24}$ However, it has been reported that the cough response to distilled water inhalation is significantly related to the ACE genotype in normal subjects. ${ }^{25}$ Surprisingly, no genetic determinants of cough sensitivity have been identified in patients with chronic cough, although many studies have found that some patients with chronic cough have enhanced cough sensitivity to inhaled capsaicin. ${ }^{19} 20$ We hypothesised that genetic variations in candidate genes for cough sensitivity are associated with enhanced cough sensitivity to inhaled capsaicin, and we targeted $N K-1 R$ and $N K-2 R$ as candidate genes for cough sensitivity in patients with chronic cough.

\section{METHODS \\ Subjects}

Patients with non-productive chronic cough of more than 6 weeks' duration as the only presenting symptom were recruited from the outpatient clinic of Seoul National University Hospital. Patients with known chronic cough aetiologies such as upper respiratory tract infections within 4 weeks, posterior nasal drip syndrome or paranasal sinus abnormalities, abnormal chest radiograph, and symptoms or investigations suggestive of gastro-oesophageal reflux, and those taking cough inducing medication such as angiotensin converting enzyme inhibitor were excluded from the study. In total, 312 patients and 100 age matched healthy controls were evaluated in the association study. All subjects provided informed consent and the study protocol was approved by the ethics committee of Seoul National University Hospital.

\section{Allergy skin prick testing}

Skin prick tests were performed using 55 common aeroallergens (Allergopharma Co, Hamburg, Germany) which included Dermatophagoides pteronyssinus, D farinae, cat fur, Aspergillus fumigatus, Alternaria alternata, tree pollens, grass pollens, weed pollens, and cockroach. A positive histamine $(1 \mathrm{mg} / \mathrm{ml}$ ) control and a negative diluent control were included in all the tests. Fifteen minutes after skin pricking, the mean diameters of the formed wheals were compared with those formed by histamine. If the former was the same as or larger than the latter (that is, an allergen:histamine ratio $\geqslant 1.0$ ), the reaction was defined as positive. Atopy was defined as positive responses to one or more aeroallergens.

\section{Capsaicin provocation testing}

Capsaicin provocation challenges were performed as described previously. ${ }^{1621}$ Briefly, subjects inhaled a single deep breath of saline containing doubling concentrations of capsaicin (Sigma Chemical Co, St Louis, MO, USA) within the range of $2.5-500 \mu \mathrm{mol} / \mathrm{l}$ at 180 second intervals. Capsaicin inhalation was controlled using a DeVilbiss 646 nebuliser (DeVilbiss, Somerset, PA, USA) connected to a dosimeter. The number of coughs induced in response to the saline and to each concentration of capsaicin was counted during and 60 seconds after each inhalation. At these capsaicin concentrations, 245/312 (78.5\%) patients with chronic cough had more than five consecutive coughs. The lowest capsaicin concentration that elicited at least five consecutive coughs $(\mathrm{C} 5, \mu \mathrm{M} / \mathrm{l})$ was calculated and used as an index of cough sensitivity. The response to the capsaicin provocation test was regarded as positive if C5 was $<16 \mu \mathrm{M} / \mathrm{l}$.

\section{Genotyping of NK-1R and NK-2R \\ SNP discovery}

Genomic DNA samples were extracted from the peripheral blood of 49 healthy subjects without respiratory symptoms using the Wizard Genomic DNA Purification Kit (Promega Corp, Madison, WI, USA). All of the $N K-1 R$ and $N K-2 R$ exons were amplified using primers designed by the OLIGO Primer Analysis version 5 software (Molecular Biology Insights Inc, Cascade, CO, USA; table 1). Sequencing was performed using the Big Dye Terminator kit (Applied Biosystems, Foster City, CA, USA) and the ABI Prism 3100 automatic DNA sequencer (Applied Biosystems). From the sequencing of the $N K-2 R$ gene, two non-synonymous informative SNPs with minor allele frequencies $>1 \%$ were discovered. Non-synonymous informative SNPs were not found for the NK-IR gene.

\section{SNP scoring}

The frequencies for the two non-synonymous SNPs in $N K-2 R$ (Gly231Glu and Arg375His) were scored using the single base pair extension method for the chronic cough patients and healthy controls. The primers 5'-CTGGAGGCTCGCAGT GCCCG-3' and 5'-TACCAGTGGGGAGGCGGGGC-3' were used to amplify Gly231Glu and Arg375His, respectively. Primer extension reactions were performed using the SNaPshot ddNTP Primer Extension Kit (Applied Biosystems) according to the manufacturer's instructions.

\begin{tabular}{|c|c|c|c|}
\hline Gene & Region & & Primers \\
\hline \multirow[t]{9}{*}{ NK-IR } & Exon 1 & $\begin{array}{l}\text { Sense } \\
\text { Antisense }\end{array}$ & 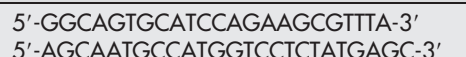 \\
\hline & Exon 2 & Sense & 5'-GGTTCTATGAATTITCTTATTGGC- $3^{\prime}$ \\
\hline & & Antisense & $5^{\prime}$-CAACCTGATATGAGGGTATATGTGA-3' \\
\hline & Exon 3 & Sense & $5^{\prime}$-TGCCAAACCTTGACTGCAATAACA-3' \\
\hline & & Antisense & 5'-GTCTGTGCCAGGGTGGGTAGT \\
\hline & Exon 4 & Sense & 5'-GTGGTCTCACCTGTCTCACCCTC-3' \\
\hline & & Antisense & $5^{\prime}$-CGCTTGGCCACTGTGTATGTAGA-3' \\
\hline & Exon 5 & Sense & 5'-AAAGGTCACCTCTTCATCTGCTCGC-3' \\
\hline & & Antisense & 5'-GCATGAGGGTGGCAAAGATAGGGA-3' \\
\hline \multirow[t]{10}{*}{ NK-2R } & Exon 1 & Sense & 5'-CAAATCCGAGAGGAGCCGAGGAG-3' \\
\hline & & Antisense & 5'-GCATGTCACCACCCTTATTCGAGCC-3' \\
\hline & Exon 2 & Sense & 5'-GCCCTCTGCTCACAGGTACATGG- $3^{\prime}$ \\
\hline & & Antisense & 5'-GGCTTACAGGAGGAGCGTCTTGC-3' \\
\hline & Exon 3 & Sense & 5'-GCAGGTACCACCTCGTGGTGATCGC-3' \\
\hline & & Antisense & 5'-TCTCTTGGCCTGCAGATGGCGGAG-3' \\
\hline & Exon 4 & Sense & 5'-GGACCAGGTGTTGTGAAGACCAT-3' \\
\hline & & Antisense & 5'-CTGTGGIGAGACAGCAGTAGA-3' \\
\hline & Exon 5 & Sense & 5'-CTCTGGGTCCGGCTTGCCT-3' \\
\hline & & Antisense & 5'-ACACCTCCCACTAACCCCTACCTGC-3' \\
\hline
\end{tabular}




\begin{tabular}{|c|c|c|c|c|}
\hline Genotypes & & $\begin{array}{l}\text { Patients } \\
(\mathrm{N}=312)\end{array}$ & $\begin{array}{l}\text { Controlst } \\
(\mathrm{N}=100)\end{array}$ & p value ${ }^{*}$ \\
\hline \multirow[t]{3}{*}{ Codon 231} & Gly/Gly & $107(36.5 \%)$ & $30(30 \%)$ & 0.87 \\
\hline & Gly/Glu & $131(44.7 \%)$ & $50(50 \%)$ & \\
\hline & Glu/Glu & $55(18.8 \%)$ & $20(20 \%)$ & \\
\hline \multirow[t]{3}{*}{ Codon 375} & $\mathrm{Arg} / \mathrm{Arg}$ & 229 (78.7\%) & 79 (79\%) & 0.83 \\
\hline & $\mathrm{Arg} / \mathrm{His}$ & 56 (19.2\%) & $17(17 \%)$ & \\
\hline & $\mathrm{His} / \mathrm{His}$ & $6(2.1 \%)$ & $4(4 \%)$ & \\
\hline \multirow[t]{4}{*}{ Haplotypes } & 231Gly_375Arg & $47.8 \%$ & $42.5 \%$ & 0.69 \\
\hline & $231 \mathrm{Gly} 375 \mathrm{His}$ & $11.1 \%$ & $12.5 \%$ & \\
\hline & 231Glu_375Arg & $40.5 \%$ & $45.0 \%$ & \\
\hline & 231Glu_375His & $0.4 \%$ & $0 \%$ & \\
\hline
\end{tabular}

To clean up the primer extension reaction products, I U SAP was added to the reaction mixture and the mixture was incubated for 1 hour at $37^{\circ} \mathrm{C}$, and then for 15 minutes at $72^{\circ} \mathrm{C}$ to inactivate the enzyme. The samples that contained the extension products and the Genescan 120 Liz size standard were added to Hi-Di formamide (Applied Biosystems), as recommended by the manufacturer, incubated at $95^{\circ} \mathrm{C}$ for 5 minutes, placed on ice for 5 minutes, and then electrophoresed using the ABI Prism 3100 Genetic Analyzer. After SNP scoring, complete genotyping data were obtained for 291 patients with chronic cough and 100 healthy control subjects.

\section{Statistical analysis}

Individual SNPs and haplotypes were examined as a threecomponent variable-for example, $\mathrm{AA}, \mathrm{AB}$, and $\mathrm{BB}$, where $\mathrm{A}$ is the major frequency allele or haplotype and $\mathrm{B}$ is the minor frequency allele or haplotype. The haplotypes and their frequencies were analysed using the ExpectationMaximisation (EM) algorithm. ${ }^{26}$ To determine whether one of the homozygous genotypes had an effect that differed from the common effects of the heterozygous genotype and the other homozygote ( $\mathrm{AA}$ versus $\mathrm{AB}+\mathrm{BB}$ or $\mathrm{BB}$ versus $\mathrm{AB}+\mathrm{AA}$, dominant or recessive models, respectively), a $2 \times 2$ contingency table was drafted and the $\mathrm{p}$ value was obtained using $\chi^{2}$ tests for categorical variables. As the continuous variable C5 exhibited a right skew, statistical significance was evaluated using non-parametric methods such as the Mann-Whitney and Kruskal-Wallis tests. To determine the odds ratio (OR) and 95\% confidence interval (CI), multiple logistic regression modelling was performed to adjust for confounding variables such as age, sex, smoking history, and atopy. Allele frequency distributions were tested for Hardy-Weinberg equilibrium using the $\chi^{2}$ test. A $p$ value of $\leqslant 0.05$ was regarded as being statistically significant. All of the statistical analyses were performed with SAS software version 8.1 (SAS, Cary, NC, USA).

\section{RESULTS}

The DNA sequencing revealed two informative non-synonymous SNPs in NK-2R (Gly231Glu in exon 3, and Arg375His in exon 5), whereas non-synonymous SNPs were not found in $N K-1 R$. The genotype frequencies for the subjects were: homozygous Gly, 32.7\%; Gly/Glu, 46.9\%; homozygous Glu, 20.4\% at codon 231; homozygous Arg, 75.0\%; Arg/His, 22.9\%; and homozygous His, $2.1 \%$ at codon 375 . SNP scoring was performed for 312 patients with non-productive chronic cough and 100 age matched healthy controls. The genotypic distributions of both the patients and controls were in HardyWeinberg equilibrium ( $p>0.05$, data not shown). No significant differences were found in the $N K-2 R$ genotype frequencies between the patients with chronic cough and healthy controls (table 2).

Four different haplotypes of the $N K-2 R$ gene were constructed using the EM algorithm, and linkage disequilibrium existed between the two informative SNPs $\left(\left|D^{\prime}\right|=0.9\right)$. The haplotype frequencies of the patients were 231Gly_375Arg, $47.8 \%$; 231Gly_375His, $11.1 \%$; 231Glu_375Arg, $40.5 \%$; and

\begin{tabular}{|c|c|c|c|}
\hline & \multicolumn{2}{|c|}{ Capsaicin sensitivity§ } & \multirow[b]{2}{*}{ p value* } \\
\hline & $\begin{array}{l}\text { Positive } \\
\text { ( } N=146)\end{array}$ & $\begin{array}{l}\text { Negative } \\
(\mathrm{N}=166)\end{array}$ & \\
\hline Mean (range) age (years) & $50.1(20-79)$ & $49.1(15-87)$ & 0.56 \\
\hline $\operatorname{Sex}(F / M)$ & $104 / 42$ & $100 / 66$ & 0.04 \\
\hline Smoker (\%) & 19.3 & 23.8 & 0.32 \\
\hline Atopy $\neq(\%)$ & 30.8 & 25.5 & 0.32 \\
\hline \multicolumn{4}{|l|}{ Gly231 Glu, N (\%) } \\
\hline Gly/Gly & $45(32.6 \%)$ & $62(40.0 \%)$ & \multirow{3}{*}{0.004} \\
\hline Gly/Glu & $56(40.6 \%)$ & 75 (48.4\%) & \\
\hline Glu/Glu & $37(26.8 \%)$ & $18(11.6 \%)$ & \\
\hline \multicolumn{4}{|l|}{ Arg375His, N (\%) } \\
\hline Arg/Arg & 114 (83.2\%) & 115 (74.7\%) & \multirow{3}{*}{0.12} \\
\hline Arg/His & $20(14.6 \%)$ & $36(23.4 \%)$ & \\
\hline $\mathrm{His} / \mathrm{His}$ & $3(2.2 \%)$ & $3(1.9 \%)$ & \\
\hline \multicolumn{4}{|c|}{$\begin{array}{l}\text { * } \chi^{2} \text { test (positive } v \text { negative capsaicin sensitivity). } \\
\text { †Positive skin test responses to one or more common aeroallergens. } \\
\ddagger \text { A recessive model of an allele (Glu/Glu vother alleles); OR } 1.69 \text { ( } 95 \% \mathrm{Cl} 1.18 \text { to } 2.42 \text { ) by multiple logistic } \\
\text { regression analysis after adjusting for confounders such as age, sex, smoking history, and atopy. } \\
\S C 5 \leqslant 16 \mu \mathrm{M} / \mathrm{l} \text {. }\end{array}$} \\
\hline
\end{tabular}




\begin{tabular}{|c|c|c|c|c|}
\hline \multirow[b]{2}{*}{ Genotype } & \multirow[b]{2}{*}{$N$} & \multicolumn{2}{|c|}{$\mathrm{C} 5+(\mu \mathrm{M} / \mathrm{l})$} & \multirow[b]{2}{*}{ p value* } \\
\hline & & Mean & SD & \\
\hline \multicolumn{5}{|l|}{ Gly231Glu } \\
\hline Gly/Gly & 70 & 62.4 & 56.2 & \multirow{3}{*}{$0.04 \ddagger$} \\
\hline Gly/Glu & 115 & 60.0 & 55.8 & \\
\hline Glu/Glu & 52 & 44.1 & 53.2 & \\
\hline \multicolumn{5}{|l|}{ Arg375His } \\
\hline Arg/Arg & 191 & 54.2 & 55.1 & \multirow{3}{*}{0.17} \\
\hline $\mathrm{Arg} / \mathrm{His}$ & 39 & 72.0 & 57.3 & \\
\hline $\mathrm{His} / \mathrm{His}$ & 6 & 68.6 & 65.1 & \\
\hline $\begin{array}{l}\text { *Non-paran } \\
\text { †The lowest } \\
\text { tln a recess }\end{array}$ & a don & $\begin{array}{l}\text { an allele, } \\
\text { consec } \\
\text { uv). }\end{array}$ & $\begin{array}{l}\text { erwise } \\
\text { s. }\end{array}$ & \\
\hline
\end{tabular}

231 Glu_375His, $<0.1 \%$, which were similar to those of healthy controls (table 2 ).

Based on the hypothesis that the non-synonymous SNPs in $N K-2 R$ are associated with enhanced cough sensitivity in patients with chronic cough, patients were asked to undergo capsaicin bronchial challenges. The parameters of age, smoking status, and atopy (defined as a positive skin response to one or more common aeroallergens) were similar in 146 patients with enhanced capsaicin sensitivity and in 166 patients with normal capsaicin sensitivity, although the percentage of women was higher in the former group (table 3). The rate of enhanced capsaicin sensitivity was significantly higher in those patients with the $231 \mathrm{Glu}$ allele $(\mathrm{p}=0.004$ in a recessive model; OR $(95 \% 1.69$ (95\% CI 1.18 to 2.42)), whereas this rate was not associated with the Arg375His allele (table 3 ).

The levels of C5 (the lowest capsaicin concentration that elicited five consecutive coughs, $\mu \mathrm{M} / \mathrm{l}$ ) were not different on the basis of age, sex, smoking status, or atopy (data not shown). However, C5 was significantly lower in those patients with the 231 Glu allele (mean (SD) 44.1 (53.2) $v$ 60.9 (55.8); $p=0.04$ in a recessive model), although the C5 levels were not associated with the Arg375His allele (table 4).

In terms of an association between NK-2R SNP haplotypes and the rate of cough sensitivity to capsaicin, the prevalence of enhanced capsaicin sensitivity was significantly higher in those patients with the 231Glu_375Arg haplotype than in those with other haplotypes $(\mathrm{p}=0.003$ in a dominant model; OR 1.71 (95\% CI 1.20 to 2.24); table 5). Even after Bonferroni's correction, the association of the 231Glu_375Arg haplotype with the rate of capsaicin sensitivity was statistically significant ( $p$ corrected $=0.012$ in a recessive model $)$. Moreover, the C5 levels were significantly lower in patients with the 231Glu_375Arg haplotype than in those with other haplotypes (43.2 (52.7) v $69.6(52.0) \mu \mathrm{M} / \mathrm{l}, \mathrm{p}=0.03$ in a recessive model, table 6).

\section{DISCUSSION}

Many studies have suggested that TKs and their receptors are involved in cough development. ${ }^{11} 1{ }^{152728}$ However, to the best of our knowledge, this is the first study to show that genetic variations of the TK receptors are significantly associated with enhanced cough sensitivity in patients with non-productive chronic cough. In terms of assessing cough sensitivity, no definitive standardised method exists for estimating neural sensory reactivity in patients with a cough. Capsaicin is commonly used as a cough stimulant in studies of cough sensitivity, and C5 is the most commonly used method for determining cough sensitivity status, although some investigators have suggested counting the total number of induced coughs after capsaicin inhalation. ${ }^{19} 2023$ We therefore evaluated capsaicin sensitivity with both qualitative (the rate of positivity) and quantitative (C5) traits. Moreover, as a qualitative trait, the positive rate of capsaicin sensitivity was strictly defined when $\mathrm{C} 5$ was $<16 \mu \mathrm{M} / \mathrm{l}$ to avoid borderline cases of enhanced capsaicin sensitivity. ${ }^{14}$

Several host and environmental factors such as age, sex, smoking, and atopy may affect cough sensitivity to capsaicin. ${ }^{21-23}$ Kastelik and co-workers have suggested that females predominate in the population of patients with chronic cough with enhanced capsaicin sensitivity. ${ }^{21}$ In terms of the effect of smoking on cough sensitivity, some studies have suggested that capsaicin cough sensitivity is decreased in smokers while others have reported that chronic tobacco smoke exposure increases cough sensitivity. ${ }^{22}$ The present study shows that C5 levels do not differ in relation to risk factors such as age, smoking status, and atopy, although the proportion of females was higher in the group of patients with enhanced capsaicin sensitivity. This finding suggests that factors other than smoking and atopy are important in determining cough sensitivity.

TKs are a family of neuropeptides that share the common carboxyl terminal sequence Phe-X-Gly-Leu-Met-NH2. ${ }^{29}$ SP

Table 5 Haplotype frequencies of non-synonymous SNPs of the NK-2R gene in relation to the capsaicin sensitivities of patients with chronic cough

\begin{tabular}{|c|c|c|c|c|}
\hline \multirow[b]{2}{*}{ Haplotype } & \multicolumn{2}{|c|}{ Capsaicin sensitivity $†$} & \multirow[b]{2}{*}{ p value* } & \multirow[b]{2}{*}{ OR $(95 \% \mathrm{Cl}) \ddagger$} \\
\hline & Positive (\%) & Negative (\%) & & \\
\hline 231Gly_375Arg & 43.9 & 51.3 & 0.06 & $0.72(0.51$ to 1.02$)$ \\
\hline $231 \mathrm{Gly} 375 \mathrm{His}$ & 9.0 & 13.0 & 0.12 & $0.66(0.38$ to 1.12$)$ \\
\hline 231Glu_375Arg & 46.8 & 35.8 & $0.01 \S$ & $1.71(1.20$ to 2.24$)$ \\
\hline $231 \mathrm{Glu} 375 \mathrm{His}$ & 0.3 & 0.3 & 0.92 & 0.87 (0.05 to 14.09$)$ \\
\hline
\end{tabular}

${ }^{*} \chi^{2}$ test in a dominant model of a haplotype ( $\mathrm{ht} / \mathrm{ht}+\mathrm{ht} /$ others $v$ other haplotypes). †C5 $\leqslant 16 \mu \mathrm{M} / \mathrm{l}$.

$\ddagger$ Multiple logistic regression analysis after adjusting for confounding factors such as age, sex, smoking, and atopy $\S p$ value corrected by Bonferroni's method (uncorrected $p=0.003$ ) 
Table 6 Association between the quantitative trait of capsaicin sensitivity (C5) and NK$2 R$ gene haplotypes in patients with chronic cough

\begin{tabular}{|c|c|c|c|c|}
\hline \multirow[b]{2}{*}{ Haplotypes } & \multirow[b]{2}{*}{$\mathrm{N}$} & \multicolumn{2}{|c|}{$\mathrm{C} 5+(\mu \mathrm{M} / \mathrm{I})$} & \multirow[b]{2}{*}{ p value* } \\
\hline & & Mean & SD & \\
\hline 231Gly_375Arg/231Gly_375Arg & 39 & 64.1 & 56.6 & \\
\hline 231Gly_375Arg/231Gly_375His & 26 & 60.9 & 56.3 & \\
\hline 231Gly_375Arg/231Glu_375Arg & 107 & 55.8 & 54.8 & $0.03 \ddagger$ \\
\hline 231Gly_375His/231Glu_375Arg & 11 & 99.1 & 52.0 & \\
\hline 231Glu_375Arg/231Glu_375Arg & 50 & 43.2 & 52.7 & \\
\hline
\end{tabular}

and NKA, but not NKB, are localised to a population of sensory neurons in the respiratory tract. ${ }^{30}$ These peptides have potent effects on bronchomotor tone, airway secretions, bronchial circulation, and inflammatory and immune cells. ${ }^{18}$ The biological actions of TKs are mediated by NK-1R (preferentially activated by substance P), NK-2R (preferentially activated by NKA); and NK-3R (preferentially activated by $\mathrm{NKB}$ ), which belong to the $\mathrm{G}$ protein coupled receptor family. ${ }^{17} 29$

The importance of SP and NKA in cough development is supported by the following observations. Firstly, in conscious guinea pigs, very low concentrations of inhaled SP are reported to cause cough and this effect is potentiated by neural endopeptidase inhibition. ${ }^{27}$ Secondly, citric acidinduced cough is blocked by the NK-2R antagonist SR $48968{ }^{31}$ Thus, in the present study, we targeted the $N K-1 R$ and $N K-2 R$ genes which encode mammalian TRs that have a similar structural organisation and contain five exons, with introns interrupting the protein coding sequences at identical positions. ${ }^{29}{ }^{32}$ The gene that encodes NK-1R is located on chromosome $2 \mathrm{pll}$. As for the genetic polymorphisms of $N K$ $I R$, one synonymous cSNP (PhelllPhe) has been reported. However, we found no non-synonymous SNPs for the NK-IR gene of Koreans. On the other hand, the gene that encodes NK-2R is located on chromosome 10q11-21. A search of the database showed four synonymous cSNPs and two nonsynonymous cSNPs (Thr23Ile, rs5030920 and His375Arg, rs2229170) for the $N K-2 R$ gene. Interestingly, we found two informative non-synonymous SNPs of $N K-2 R$ (Gly231Glu and His375Arg), one of which (Gly231Glu) proved to be novel.

Although chronic cough is known to be a complex genetic phenotype that is determined by multiple genetic and environmental factors, ${ }^{15}$ there are few data available on the genetic determinants of the generation of chronic cough. ${ }^{33}$ The present study shows that the frequencies of non-synonymous SNPs in the $N K-2 R$ gene are similar in patients with chronic cough and in age matched healthy controls, which suggests that genetic variations in genes other than $N K-2 R$ are involved in susceptibility to chronic cough development.

Cough sensitivity may also be a complex phenotype that is determined by complex interactions between genetic and environmental factors. ${ }^{512534}$ However, to date, genetic determinants of cough sensitivity have received little attention. ${ }^{34}$ Interestingly, the present study shows that capsaicin sensitivity, as evaluated both qualitatively and quantitatively, is enhanced in patients with the 231Glu allele but is not associated with the Arg371His genotype. Codon 231 of NK-2R corresponds to the third intracellular loop of the receptor, which is important in agonist stimulated second messenger responses. ${ }^{35}$ The Gly to Glu substitution in the Gly231Glu genotype may alter the nature of the cytoplasmic loop in NK$2 \mathrm{R}$ through the substitution of the larger negatively charged polar glutamic acid for the polar uncharged glycine. Interestingly, in the guinea pig trachea, TKs potentiate cholinergic neurotransmission (effector pathway of cough reflex) by increasing acetylcholine release, which is NK-2Rdependent. ${ }^{17}$ Taken together, these findings suggest that genetic variations in $N K-2 R$ are involved in cough sensitivity to a stimulus.

The present study also shows that capsaicin sensitivity is significantly associated with the 231Glu_375Arg haplotype. Even after Bonferroni's correction, the association of the 231Glu 375Arg haplotype with the positive rate of capsaicin sensitivity was statistically significant. However, the statistical power of the genetic association was similar for the $231 \mathrm{Glu}$ allele alone. This finding suggests that the $231 \mathrm{Glu}$ allele is a more important genetic marker in terms of predisposition to cough sensitivity to capsaicin. However, it is important to note that this finding does not by itself confirm conclusively an aetiological relationship between this polymorphism and capsaicin sensitivity in patients with chronic cough.

In summary, this is the first study to address the possible influence of $N K-2 R$ polymorphisms on cough sensitivity to capsaicin. We show that the $231 \mathrm{Glu} \rightarrow$ Gly polymorphism is associated with enhanced cough sensitivity to capsaicin in patients with chronic cough, despite the lack of an association with cough development. These results support the notion that this coding non-synonymous SNP of $N K-2 R$ modulates NK-2R signalling, thereby influencing cough sensitivity to capsaicin in patients with chronic cough.

\section{Authors' affiliations}

H-K Park, Department of Internal Medicine, Pusan National University College of Medicine, Busan, Korea

S-Y Oh, S-H Cho, K-U Min, Y-Y Kim, Department of Internal Medicine, Institute of Allergy and Clinical Immunology, Seoul National University College of Medicine, Seoul, Korea

T-B Kim, Department of Internal Medicine, Ulsan University College of Medicine, Seoul, Korea

J-W Bahn, Department of Internal Medicine, Hallym University College of Medicine, Seoul, Korea

E-S Shin, J-E Lee, DNA Link, Seoul, Korea

H-B Oh, Department of Diagnostic Medicine, Ulsan University College of Medicine, Seoul, Korea

Y-K Kim, Department of Life Science, Pohang University of Science and Technology, Pohang, Korea

T Park, Department of Statistics, Seoul National University, Seoul, Korea

This study was supported by a grant (03-PJ10-PG13-GD01-0002) from the Korea Health 21 R\&D Project, Korean Ministry of Health \& Welfare. The work of T Park was partially supported by the National Research Laboratory Program of Korea Science and Engineering Foundation.

Competing interests: none declared.

\section{REFERENCES}

1 Irwin RS, Curley FJ, French CL. Chronic cough. The spectrum and frequency of causes, key components of the diagnostic evaluation, and outcome of specific therapy. Am Rev Respir Dis 1990;141:640-7. 
2 Morice AH, Epidemiology of cough. Pulm Pharmacol Ther 2002;15:253-9.

3 Pratter MR, Bartter T, Akers S, et al. An algorithmic approach to chronic cough. Ann Intern Med 1993;119:977-83.

4 Ing AJ, Ngu MC, Breslin AB. Pathogenesis of chronic persistent cough associated with gastroesophageal reflux. Am J Respir Crit Care Med 1994; 149:160-7

5 Fujimura M. Eosinophilic bronchitis is an important cause of chronic cough. Am J Respir Crit Care Med 2000;161:1764-5.

6 Widdicombe JG. Neurophysiology of the cough reflex. Eur Respir J 1995;8:1193-202.

7 Coleridge HM, Coleridge JC. Impulse activity in afferent vagal C-fibres with endings in the intrapulmonary airways of dogs. Respir Physiol 1977;29:125-42

8 Forsberg K, Karlsson JA. Cough induced by stimulation of capsaicin-sensitive sensory neurons in conscious guinea-pigs. Acta Physiol Scand 1986; 128:319-20.

9 O'Connell F. Central pathways for cough in man-unanswered questions. Pulm Pharmacol Ther 2002;15:295-301.

10 Fujimura M, Kamio Y, Myou S, et al. Effect of oral mexiletine on the cough response to capsaicin and tartaric acid. Thorax 2000;55:126-8.

11 Groneberg DA, Niimi A, Dinh QT, et al. Increased expression of transient receptor potential vanilloid-1 in airway nerves of chronic cough. Am J Respir Crit Care Med 2004; 170:1276-80.

12 Forsberg $\mathrm{K}$, Karlsson JA, Theodorsson $\mathrm{E}$, et al. Cough and bronchoconstriction mediated by capsaicin-sensitive sensory neurons in the guinea-pig. Pulm Pharmacol 1988;1:33-9.

13 Ogawa H, Fujimura M, Saito $M$, et al. The effect of the neurokinin antagonist $\mathrm{K}-224$ on the cough response to inhaled capsaicin in a new model of guineapig eosinophilic bronchitis induced by intranasal polymyxin B. Clin Auton Res 1994;4:19-28.

14 Cho YS, Park SY, Lee CK, et al. Elevated substance P levels in nasal lavage fluids from patients with chronic nonproductive cough and increased cough sensitivity to inhaled capsaicin. J Allergy Clin Immunol 2003;112:695-701.

15 Maggi CA. Tachykinin receptors and airway pathophysiology. Eur Respir J 1993;6:735-42.

16 Barnes PJ. Sensory nerves, neuropeptides, and asthma. Ann NY Acad Sci 1991;629:359-70.

17 Hall AK, Barnes PJ, Meldrum LA, et al. Facilitation by tachykinins of neurotransmission in guinea-pig pulmonary parasympathetic nerves. $\mathrm{Br} J$ Pharmacol 1989;97:274-80.

18 Hay DW, Giardina GA, Griswold DE, et al. Nonpeptide tachykinin receptor antagonists. III. SB 235375, a low central nervous system-penetrant, potent and selective neurokinin-3 receptor antagonist, inhibits citric acid-induced cough and airways hyper-reactivity in guinea pigs. J Pharmacol Exp Ther 2002;300:314-23.
19 Doherty MJ, Mister R, Pearson MG, et al. Capsaicin responsiveness and cough in asthma and chronic obstructive pulmonary disease. Thorax 2000;55:643-9.

20 Weinfeld D, Ternesten-Hasseus E, Lowhagen O, et al. Capsaicin cough sensitivity in allergic asthmatic patients increases during the birch pollen season. Ann Allergy Asthma Immunol 2002;89:419-24.

21 Kastelik JA, Thompson RH, Aziz I, et al. Sex-related differences in cough reflex sensitivity in patients with chronic cough. Am J Respir Crit Care Med 2002; 166:961-4.

22 Bergren DR. Chronic tobacco smoke exposure increases cough to capsaicin in awake guinea pigs. Respir Physiol 2001;126:127-40.

23 Millqvist E, Bende M. Capsaicin cough sensitivity is decreased in smokers. Respir Med 2001;95:19-21.

24 McGarvey LP, Savage DA, Feeney SA, et al. Is there an association between angiotensin-converting enzyme gene variants and chronic nonproductive cough? Chest 2000;118:1091-4.

25 Morice AH, Turley AJ, Linton TK. Human ACE gene polymorphism and distilled water induced cough. Thorax 1997:52:111-3.

26 Excoffier L, Slatkin M. Maximum-likelihood estimation of molecular haplotype frequencies in a diploid population. Mol Biol Evol 1995;12:921-7.

27 Birring SS, Parker D, Brightling CE, et al. Induced sputum inflammatory mediator concentrations in chronic cough. Am J Respir Crit Care Med 2004:169:15-9.

28 Kohrogi H, Graf PD, Sekizawa K, et al. Neutral endopeptidase inhibitors potentiate substance $P$ - and capsaicin-induced cough in awake guinea pigs. J Clin Invest 1988;82:2063-8.

29 Pennefather JN, Lecci A, Candenas ML, et al. Tachykinins and tachykinin receptors: a growing family. Life Sci 2004;74:1445-63.

30 Barnes PJ, Baraniuk JN, Belvisi MG. Neuropeptides in the respiratory tract. Part I. Am Rev Respir Dis 1991; 144:1 187-98.

31 Advenier C, Girard V, Naline E, et al. Antitussive effect of SR 48968, a nonpeptide tachykinin NK2 receptor antagonist. Eur J Pharmacol 1993;250:169-71.

32 Gerard NP, Garraway LA, Eddy RL, et al. Human substance P receptor (NK1): organization of the gene, chromosome localization, and functional expression of CDNA clones. Biochemistry 1991;30:10640-6.

33 Mukae $\mathrm{S}$, Aoki $\mathrm{S}$, Itoh $\mathrm{S}$, et al. Bradykinin $\mathrm{B}(2)$ receptor gene polymorphism is associated with angiotensin-converting enzyme inhibitor-related cough. Hypertension 2000;36:127-31.

34 Furuya K, Yamaguchi E, Hirabayashi T, et al. Angiotensin-l-converting enzyme gene polymorphism and susceptibility to cough. Lancet 1994;343:354.

35 Blount P, Krause JE. The roles of the putative third cytoplasmic loop and cytoplasmic carboxyl tail of NK-1 and NK-2 receptors in agonist stimulated second messenger responses in stably transfected $\mathrm{CHO}$ cells. Regul Pept 